\title{
Application of Psychology in healing the problems in Humanitarian logistics
}

\author{
${ }^{1}$ Kanagaraj.K, ${ }^{2}$ Dr.Joy Mukhopadhyay \\ ${ }^{1}$ Designation \& Affiliation : Asst.Prof-ISBR Business School,Electronic city, Banaglore, India. 560100 \\ ${ }^{2}$ Designation \& Affiliation : Professor - ISBR Bangalore
}

\begin{abstract}
Disasters in general leave a long lasting impact on the mankind \& society as a whole. The materialistic damage that it causes have a chance to be reinstated to a major extent but the internal psychological damage that it causes to the people takes ages to heal and sometimes remains unhealed as not much help is available in that area. In this paper we have analyzed the psychological problems faced by the rescuers and victims during and after the disaster starting from day 1 to day 30 of the disaster, beginning from facing the victim in the field to rehabilitation of the victim after the disaster. The research methodology includes expert opinions and focus group discussions from various stake holders of Disaster management including psychologists, NGO, Defense personnel and academicians who are involved in the teaching of Disaster management. Detailed interviews were also conducted of the rehabilitated victims of disasters; reports from the media have also been referred. We have limited our study to Natural \& Manmade Disasters excluding civil commotions, riots and wars. The paper is conceptual in nature and it aims at providing suggestions and possible solutions on the psychological problems identified during the research
\end{abstract}

Keywords: Humanitarian Logistics, Psychology, Disaster management

\section{Introduction}

In the last few months the Indian subcontinent has been hit with major disasters that had caused devastations leading to the loss of millions of dollars in terms of money and irreversible psychological damage to the concerned people and society at large. In this era of science and technology where the forecasting system is at its best we are able to minimize the damage that is caused to the materialistic world but the scars of the human tragedy in the minds of the affected people remain for a very long time. Although it's true that human life cannot be compensated, we need to figure out how to deal with these circumstances as this can happen to anyone, anybody and anywhere.

Most of the humanitarian logistic models focus only on time as the most important factor in a crisis, as they want to reach and provide aid at the shortest possible time. They neglect the psychological aspects of the same and of course cost is not to be accounted as that is the least priority. Please remember that the first point of contact of the victim in a rescue mission is usually the service personnel from the fire department or the defense services. There are 2 major problems that are generally not taken into consideration but have a substantial effect on the society. The first being the psychological impact to the rescuers and victims during the first 10 days of evacuation, the second being the relief materials (in terms of quality, quantity, type) becoming hindrance to the relief activities itself and the third the rehabilitation part that starts after day 20 .

A few anecdotes the ICHL conference 2013:

" I landed into a pit from a helicopter on a rescue mission during Uttarakhand (India) floods consisting of few people when I asked the person to move and board the helicopter he did not move, 10 minutes passed again I requested he did not move, 10 more minutes passed he still stood like a rock and then said why should I go those 2 dead who are in front of him are his kids and the 2 dead at the back of him are his parents and the whereabouts of his wife was unknown." Under these circumstances the Lt.General Anil Chait who was heading this operation was indeed dumb stuck and then managed to get him on board but was not able answer his question

Another incident where a 5 year old was abandoned by his parents during the floods, and the boy has survived, what happens next? Neither he nor anyone else has any clue about it. Plenty of such incidents happen and are conveniently ignored and forgotten.

\section{Review of Literature}

There is a considerable amount of literature available in the west but for India its considerable new topic. The Australian emergency management institute and Australian institute of traumatic stress studies have taken these psychological aspects of disasters into account and have inducted a manual as guidelines which have been endorsed by the National emergency management committee of Australia. However there are very few 
articles available on the psychological aspects of the rescuers involved in the rescue operations .Plenty of research can be done in that area. Advances in disaster mental health and psychological support - edited by Diaz and Murthy gives a detailed analysis of psychiatry during disasters. The UN has provided IRDL guidelines and many including Redcross has adopted them.

\section{The problem statement(s) and Possible Suggestions}

The bigger question how do we deal with these tragedies, its easy to seek death than be traumatized by it, but as a society we have to survive and move forward. How do we make these people believe that they are important and there life is as valuable as any other life in spite of all losses? We are not talking of resettlement or rehabilitation that comes only after this, we are only discussing about the first 10 days of the disaster where people witness only destruction of lives and livelihood, those 10 days that no one wants to face. There are two distinct actors in these conditions the victim and the rescuer.

The help rendered by humanitarian agencies provide only medicine, food etc the rescuers are not psychologically prepared to handle these situations. Confronting death (as in a funeral) is different but confronting people who are willing to die is very different. How do we prepare these people, be it of the Defense forces/other services such as fire or of the NGO or the local administrators to remain motivated to carry on the tasks and also motivate the victims to stay alive?

The next actor the victim for whom the world has come to an end be asked to continue the journey of life with no hope of life and meaning of existence in their hearts. Their have no idea how to cope with uncertainties of future.

Keeping these 2 actors in mind what can we do to solve these issues? There is no readymade solution as we cannot draw any parallels from any where; a simple focus group discussion from both the actors provided a few clues from where we can probably take it forward.

First the people who are going to be the first point of contact during a disaster (the rescuers) have to be psychologically trained to deal with these circumstances, training them will be difficult task as we cannot recreate a disaster but only visualize it. Second on the ground where the disaster strikes the recue team should include a psychologist who can handle dangerous and difficult situations preferably from the local population. Thirdly spirituality can play a major role in these circumstances as the last resort everyone looks at is god. Fourth the administrators of the local population have to be trained enough to handle these situations, but sometimes the local administration are themselves a part of the victims.

Apart from these some basic changes in the education system especially in the primary classes should be based on the LSBE (Life skills based education) pattern of the UNICEF. The education should make them mentally strong to face these challenges and emerge with more strength. Once if we conquer these first 10 days of tragedy successfully we can concentrate on the rehabilitation part, as by this time the victims would be in a state where they are willing to live life further not just exist.

The second major hindrance in the relief operations which is often ignored is the kind of relief material, quantity of relief material and the quality of relief material. In the 2001 Bhuj- Gujrat(India) earthquake the relief material that came from US was in the form of packed food was red meat however the majority of the population was vegetarian resulting in tremendous waste of effort, time and cost. When there was huge outpour of relief materials during the flood caused because of the 1999 Odisha cyclone, also known as Cyclone 05B, and Paradip cyclone there was only one stadium that was left out to carry our relief tasks all the entrances and exits to the stadium was blocked for more than 10 kilometers because of the incoming relief materials making every thing coming to a stand still for more than 2 days, the cooked food got spoilt the medicines were there at the end of the queue so they rescuers had to wait for it to come to proceed with medical services. It is also important that the relief material that being dispatched by other NGO agencies specially from with in India who tend to collect relief material form across the country and then send it to the affected areas in these circumstances the relief material has to be checked for quality as more than $50 \%$ of such materials become a waste as even beggars will not take such material. It is necessary to understand that giving or providing relief material to the agencies is not a way to dispose our old unused and useless stuff. Too much of relief material dumped can become an economic problem in that area, for example when biscuits and groceries were dumped in a village during the Uttarakhand floods in India the village shops were shut down as there was no one to buy any thing the kind of relief that would have best suited there should be monetary in nature not in terms of materials.

Coping with these challenges becomes a herculean task as all local population and the local administrators become the primary victim's, entire connectivity to the area and every single data is missing or lost. With these constraints to organize relief becomes a challenge. So what can be done, here are a few suggestions from experts of logistics. Firstly we have to use technology appropriately the local needs have to updated at least once in a month regarding the population their habits of eating the climatic conditions demographic data of children, women and senior citizens of the area on a common platform such as website and 
that data needs to centralized in place so that it forms a basis for the relief activities, all these information has to centrally linked to the UN as well so that coordination among countries can be made easy. The relief materials have to be tagged so that identification and tracking becomes easy (RFID can be used as suggested by a research paper in ICHL conference in IIM Raipur India) once indentified and tagged priorities can be set on that basis. The entire relief material should be checked by a trained person who can segregate and assess the quality of materials before it is being dispatched.

The third major concern is the trauma of rehabilitation, most of the government agencies and NGO's fail here as they have little idea of how to establish a new society with a new social order that can sustain by itself in due course of time. The PSTD - Post traumatic stress disorder needs to identified and counseling has to be given please remember this is also applicable to emergency workers Herman (1982). Ochberg (1993) has some suggestions with regard to that counseling relationship. The first is the normalization principle. Here the counselor helps the person to understand that post traumatic stress disorder is a normal response to an abnormal event, or series of events. This reorientation (away from "I" am abnormal, replaced with the trauma as abnormal) helps the person to understand that he or she is going through a process of rebalancing and healing, and that this process will require his or her involvement and patience. The fact that many persons with post traumatic stress disorders have been improperly diagnosed and improperly treated subsequently simply has added layers to their problems. Although there is very little empirical evidence available in using spirituality as way to cope trauma, but it has been successfully used by many in resettlement of refugees (Amy, Peterson, The effect of religious-spiritual coping on positive attitudes of adult Muslim refugees from Kosovo and Bosnia).Even medical science is experimenting on using spirituality as a mechanism to provide relief from many ailments (The 3H and BMSEST models for spirituality in multicultural whole-person medicine).

\section{Conclusion}

To conclude we can definitely say that the problems faced by the victims and aiders have to be overcome by proper use of psychiatry in which spirituality can be used a catalyst. The entire process is a long term process and has to be very cautiously and sincerely executed. We would require a specialized set of people to execute the same. There is no concrete framework that we can suggest as a remedy. Based on individual experience and collective experience of organizations involved in disaster management certain suggestions have been made to give better results. It is also important to note that the local culture of the area has to be taken into consideration before any planning of relief operations. As time progresses with more and more emphasis on disaster mitigation methods and newer technologies we hope that one day we will be able treat it as any other illness and keep life moving in a positive direction.

\section{References}

[1]. National center for PTSD (2005). Psychological first aid: Field operations guide

[2]. Aguirre, B.(2005). Emergency evacuations, panic and social psychology: Commentary on "Understand-ing mass panic and other collective responses to threat and disaster.” Psychiatry: Interpersonal and Biological Processes, 68(2), 121-129.

[3]. Auf der Heide, E.(2004). Common misconceptions about disasters: Panic, the disaster syndrome and looting. In M. O’Leary (Ed.), The first 72 hours: A community approach to disaster preparedness (Chapter 27). Lincoln, NE: iUniverse.Clarke, L.(2002, Aug.). Panic: myth or reality? Con-texts, 1(3), 21-26.

[4]. Clarke, L. \& Chess, C.(2008, Dec.). Elites and panic: More to fear than fear itself. Social Forces, 82(2), 993-1014. Drury, J., Cocking, C. \& Reicher, S.(2009, Sept.). Everyone for themselves? A comparative study of crowd solidarity among emergency survivors. British journal of Social Psychology, 48(3), 487-506. doi:10.1348/014466608X357893

[5]. Frey, B., Savage, D. \& Torgler, B.(2001). Behavior under extreme conditions: The Titanicdisaster. Journal of Economic Perspectives, 25(1), 209-222. doi:10.1257/jep.25.1.209

[6]. Gantt, P.(2008). Hazardous materials: Regulations, response and site operations(2nd ed.). Florence, KY: Delmar Cengage Learning [7]. Kahneman, D.(2001). Thinking, fast and slow. New York, NY: Farrar, Straus \& Giroux.

[8]. Keating, J.(1982). The myth of panic. Fire Journal, 76(3), 57-61. Mawson, A.(2005). Understanding mass panic and other collective responses to threat and disaster. Psychiatry: Interpersonal and Biological Processes, 68(2), 95-113.Myers, D.(2008).Social psychology (9th ed.). New York, NY: McGraw-Hill.

[9]. Park, Y. \& Miller, J.(2006). The social ecology of Hurricane Katrina: Rewriting the discourse of "natural" disasters. Smith College studies in Social Work, 76(3) 9-24. doi:10.1300/J497v76n03_02Pennings, J. \& Grossman, D.(2008, Sept.). Responder to crises and disasters: The role of risk attitudes and risk perceptions. Disasters, 32(3), 434-448. 